\title{
Use of Integrated Studies to Elucidate Potential Benefits from Genetic Resistance to Salmonella Carrier State in Fowl
}

\author{
Beaumont Catherine, Thanh-Son Tran, \\ Zongo Pascal, Viet Anne-France and Magal Pierre \\ French National Institute for Agricultural Research \\ UR083 Recherche Avicole, Nouzilly \\ UMR1300 Bio-agression Epidémiologie et Analyse de Risques, Nantes \\ LUNAM Université, Oniris, Nantes \\ Victor Segalen Bordeaux 2 University, Mathematics Institute of Bordeaux, Bordeaux
} France

\section{Introduction}

Salmonella, and especially Salmonella enteritidis, are one of the major causes of human toxiinfections (Humphrey, 1990), even if the trend is decreasing (European Food Safety Agency [EFSA], 2011). Many prophylactic means have thus been investigated to control the incidence of Salmonella in poultry flocks, including vaccination (Zhang-Barber et al., 1999, Curtiss et al, 2010), competitive exclusion (Nurmi \& Rantala, 1973), acidification of feed and genetic resistance. More precisely, animals' ability to clear bacteria was considered. Indeed, the absence of clinical symptoms (which is the most classical definition of resistance) does not preclude human contamination since some animals may remain contaminated for weeks or even months without showing any symptoms. Such silent carriers cannot be identified as dangerous and may therefore enter the food chain. At the opposite spectrum, animals' ability to clear bacteria will reduce the risk of transmission, first to other animals and second to humans. It will thereafter be denoted as resistance to carrier-state.

The feasibility of selection for an improved resistance to asymptomatic carriers has been demonstrated by a divergent selection experiment (\$2). Thanks to development of genomics, many results were obtained in the past 10 years: several genome regions controlling different traits were identified and the role of other genes was suggested. It will dramatically increase the efficiency of selection. With traditional selection, it is necessary to perform experimental inoculations and to slaughter animals to register the level of contamination. With marker-assisted selection and furthermore genomic selection, it will be possible to directly choose the future breeders. In addition to improved selection efficiency, it will discard the need for artificial infections. 
However, even if numerous data are currently available, strategy for application of these results are still questionable: genetic relations between resistance traits are complex and the choice of selection criteria deserves more investigations. Therefore, the whole process, leading from fowl contamination to transmission to other animals or humans was described in an integrated approach, combining genetics and other means. First results showed possible synergy between resistance and at least one another mode of prevention, vaccination. Other studies are required to compare different combinations of prophylactic means and identify new strategies for eradication of Salmonellosis, in coherence with new regulation implemented by the European Commission. They aim at reducing Salmonella prevalence in poultry flocks at less than $2 \%$ while a recent study estimated it at 29.7 and $23.7 \%$, respectively, of laying and broiler flocks, respectively, with large differences between countries (EFSA, 2007a, 2007b)

The goal of this chapter is to make a review of data currently available on the possibility of reduction of fowl carrier-state through genetic selection. It will enhance the benefits that may be obtained from an integrated approach of genetics of resistance in hens to improve the control of the incidence of Salmonella within a flock.

\section{Main results on genetics of resistance to Salmonella}

First studies were achieved very early (Lambert \& Knox, 1928; DeVolt et al., 1941) at a time when many animals died from acute salmonellosis. They thus focussed on the reduction of mortality. No experimental inoculation was needed to observe diseased animals and experiments could be achieved directly on the field. Studies focussed on serotypes pathogenic for birds (Salmonella Pullorum, Salmonella Gallinarum and Salmonella Typhimurium). Later on, the incidence of those diseases dramatically reduced with the reinforcement of preventive measures in poultry breeding. The same held for studies of resistance to Salmonella. But, in the end of the 1980's, many outbreaks of human toxiinfections due to Salmonella Enteritidis occurred, resulting in new developments in genetics of resistance to Salmonella. As in former studies, feasibility of such an approach was considered through selection experiment; genetic parameters were estimated to appreciate the response that could be expected. However, with the beginnings of molecular genetics, the research of genes controlling these traits was also addressed.

\subsection{Development of protocols of measures and identification of genetic models}

One main feature of studies of genetic resistance to Salmonella is the very large number of resistance-related traits that were considered (see Calenge et al., (2010) for a review). They differ in many factors. Inoculation by the oral route is more representative of what occurs in the field but less reproducible than the intravenous or intramuscular route. According to the Salmonella serotype, carrier-state (mostly observed after inoculation with Salmonella Enteritidis) or acute disease (mostly observed after inoculation with Salmonella Typhimurium) will be studied, but to an extent also depending, among others, on the number of inoculated bacteria. The animal's age at infection is a very important parameter. The interval between infection and observation will also be of importance, especially with reference to long-term carrier-state. Animals' conditions of rearing also influence the outcome of the infection. The susceptibility of egg to Salmonella multiplication may also be considered as described by Sellier et al. (2007). 
Many studies involve both the development of a protocol of measure of resistance and the identification, with this protocol, of lines differing in resistance. Identifying such genotypes is of great importance: their existence strongly suggests the role of genetics in the control of resistance-related traits that are measured. Genetic models for resistance or susceptibility are needed for research of genome regions controlling those traits. The first study was achieved by Bumstead \& Barrow (1988). They considered resistance to acute disease due to Salmonella Typhimurium and observed difference between partially inbred lines that are especially interesting for QTL research. Other studies addressed carrier-state and focussed on Salmonella Enteritidis. Guillot et al., (1995) observed differences in response to inoculation of chickens with a high bacterial dose. To mimic carrier-state in chicks, Duchet-Suchaux et al., (1995) developed a protocol of experimental inoculation where animals were orally infected with a low dose, showed no symptom but remained infected for several weeks. They could thus identify genetic models for further research, both outbred (Duchet-Suchaux et al., 1997) and partially inbred lines (Tilquin et al., 2005). It is to notice that the former study focussed on the same lines as in Bumstead \& Barrow, (1988). Other protocols of inoculation were developed to study persistence for a shorter term (Lamont et al., 2002; Kramer et al., 2003; Hasenstein \& Lamont, 2007).

Studies on resistance to carrier-state in adults were less numerous, in spite of importance of laying hens for the risk of human contamination. Protais et al., (1996) orally contaminated hens at the peak of lay and bacteria were searched in caeca, spleen, liver and ovary four weeks later. They observed differences between outbred poultry lines. Later on, Sadeyen et al., (2006) identified differences between inbred lines using the same protocol while Lindell et al., (1994) used a slightly different protocol.

\subsection{Response to selection}

The first selection experiment for resistance to salmonellosis after an experimental inoculation was undertaken in 1932; it proved to be efficient (Lambert, 1932). A higher resistance was observed for some breeds, among which White Leghorns (Robert and Card, quoted by Hutt \& Scholes (1941)). But De Volt et al., (1941) showed that the former were less resistant than selected Rhode Island Red hens. This result and others contributed to the development of selection for a higher resistance (see Beaumont et al., 2003a, for a review).

These results are coherent with the estimations of heritability of resistance to death $(0.15$ and 0.12) obtained respectively by Beaumont et al., (1999) after intramuscular inoculation of dayold chicks and by Janss \& Bolder (2000) after inoculation at two weeks of age. It is to notice that, according to genetic parameters estimated by the latter, more resistant animals would survive longer, contributing to a higher risk for consumers if they were still carriers. This emphasizes the importance of an increase in genetic resistance to carrier-state. An experiment of divergent selection on this trait was achieved by Beaumont et al., (2009; 2010). The base population was issued from a layer-type line. Two series of divergent lines were selected, for increased or decreased resistance at a younger age (as in Duchet-Suchaux et al., 1995) or at the peak of lay (using the protocol described by Protais et al., 1996). In adults, selection was on an all-or-none trait called global contamination, coded " 1 " if at least one organ (i.e. spleen, liver, caeca or ovary) was found positive and " 0 " in the other cases. Resistance of chicks was assessed by the logarithm of the number of colonies forming units (c.f.u.) per gram of caeca measured 5 weeks after inoculation (i.e. contamination level). A total of 3817 animals were 
thus measured (1408 adults and 2409 chicks). Clear and significant differences were observed in lines selected on adult performance, with difference in prevalence of about $20 \%$. Selection may be efficient in reducing the level of Salmonella carrier-state in hens. Differences between the "chicken" lines were, at least until now, smaller. This may be due to lower heritability but also smaller selection pressure and family sizes, due to experimental constraints and to variations in responses to infections. Indeed, in two hatches out of eight, only a small proportion of animals were still contaminated by Salmonella at slaughter; others could not be measured for level of contamination, which also slowed down selection.

Values of estimated genetic parameters were the main information from this experiment. Heritability of resistance was estimated at 0.16 in chicks while it varied from 0.14 to 0.23 with analysed organ in adult hens. It was higher in caeca $(0.23)$ while heritability of ovarian contamination was estimated at a lower value (0.11). Heritability of adult global contamination was found at 0.18 .

All genetic correlations between contamination rates of individual organs were positive, ranging from 0.46 to 0.67 . Genetic correlations between adult global contamination and contamination in individual organs were very high (from 0.75 for liver to 0.85 for spleen and caeca), except for ovary (0.32). These results are related to the central role of intestine in carrier-state of gastro-intestinal bacteria: bacteria pass through it when inoculated or after recontamination; at the opposite, contamination of other organs is dependent on translocation of intestinal barrier. Contamination of ovaries is especially rare: in this experiment only $6 \%$ of them were found contaminated versus $49 \%, 21 \%$ and $62 \%$, respectively, for spleens, livers and caeca, respectively (resulting in a percentage of contaminated adults equal to $76 \%$ ). This low rate of ovarian infection further reduced the expected response to direct selection against ovarian contamination. An indirect selection on another criterion should be more efficient. This result and the positive values of genetic correlations between contamination rates of individual organs reinforce the interest of the overall adult contamination: it is more precisely assessed and combines several traits, all of which being positively correlated.

All genetic correlations between carrier-state in chicks and production traits (egg numbers, egg weights and body weights at various ages) were small and positive (ranging from 0 to 0.37) except for the number of eggs laid between 18 and 24 weeks of age, which was slightly but negatively correlated with Salmonella load (0.17). These results suggest that selection for increased resistance may be achieved without much detrimental effect on production traits. Unlike what was observed for resistance at a younger age, genetic correlation between adult carrier-state (global contamination) and egg numbers laid at the beginning of lay (between 18 and 24 weeks of age) was positive. At the opposite, those with laying intensity at older ages were negative or very close to 0 (ranging between -0.33 and 0.01 ). Correlation with body weight at 17 weeks of age was close to 0 . These differences in genetic correlations between production traits and resistance at a younger or an older age are consistent with the negative genetic correlation observed between chicken and adult resistance.

The latter was estimated at a quite high and negative value $(-0.50)$ and the probability of the true correlation being positive was estimated at only $5 \%$. This major result holds whether overall contamination is considered or different organs distinguished and whatever the method of estimation. It is probably linked to differences in mechanisms of resistance between chicks, whose immune system is not mature, and hens, who may also benefit from 
adaptive immune response. The variation with animals' age in genetic control of adult and chicken resistance was suspected, because of differences in relative resistance of poultry lines to resistance to carrier-state at a younger (Duchet-Suchaux et al., 1997) or an older age (Protais et al., 1996). This result implies that most results obtained at a younger age are expected to be irrelevant in adults, if not of opposite sign. They may not be extrapolated to hens without experimental validation. Indeed, differences in expression of gallinacins observed by Sadeyen et al., (2004) and Sadeyen et al. (2006) were found to be associated, in young chicken, with increased susceptibility but, in adults, with resistance. Similar variations with age should also be the case of a large proportion of genes or genome regions found to be involved in resistance (for a review, see Calenge et al., 2010). This result also implies that increasing genetic resistance of hens should reduce resistance in chicks. This holds for marker-assisted or genomic selection.

\subsection{Towards identification of genes or genome regions involved in the control of resistance}

Though promising these results may seem, large-scale selection for increased resistance is very difficult to implement since experimental infections, which are both very expensive and time consuming, are required. Identifying the underlying genes of genetic markers could make it possible to alleviate the need of such experiments.

The major drawback of such genomic studies is the numbers of both phenotypes and genotypes which are required. Studying crosses between inbred lines, following the pioneer studies of Bumstead \& Barrow, $(1988 ; 1993)$ is of great relevance, as it makes it possible to identify QTLs with much less animals than with crosses between outbred lines. Backcross (Mariani et al., 2001; Lamont et al., 2002; Fife et al., 2011), F2 cross ( Tilquin et al., 2005) or, more recently, advanced intercross lines (AIL) were considered (Hasenstein et al., 2007; Ghebremichael et al., 2008) .

Candidate genes, i.e. genes chosen according to an a priori knowledge of their effect in Salmonella resistance were first investigated. That was in particular the case for two genes, SLC11A1 and TLR4, known to be involved in resistance to Salmonella in mouse. The first one corresponds to the formerly called Nramp1 (natural resistance-associated macrophage protein) gene. It is responsible for resistance of mice to inoculation with Salmonella Typhimurium, Mycobacterium bovis and Leishmania donovani (Vidal et al., 1993). Later, Nramp1 has been described as a member of a solute carrier family and hence renamed Slc11a1. It is involved in the control of the intracellular replication of parasites in phagosomes. An homologue of Nramp1 was mapped on the chicken chromosome 7 (Hu et al., 1995; Girard-Santosuosso, 1997) and subsequently cloned (Hu et al., 1996).

The second candidate gene, TLR4 (Toll-like receptor 4), previously named Lps, belongs to the large family of Toll-like receptors involved, among others, in the recognition of LPS (lipo-polysaccharides), a component specific of Gram negative bacteria (among which Salmonella). Its mutation results in a lack of response to LPS and a higher susceptibility to Gram negative bacteria. The positional cloning of Lps led to the identification of TLR4 as a positional candidate. It was mapped to the chicken micro-chromosome 17 and cloned (Leveque et al., 2003).

Hu et al., (1997) observed that both genes explained together up to $33 \%$ of the difference in survival of young chicks during the first week after an intra-muscular inoculation at one day 
of age with Salmonella Typhimurium. This difference was smaller when survival during the whole experiment was considered. The effect of the NRAMP1 gene was shown in many other experiments: in early stages of systemic Salmonella infection in meat-type chicks (Kramer et al., 2003) and layer-type hens (Lamont et al., 2002; Liu et al., 2002) or in spleen infection after intravenous inoculation of pullets (Girard-Santossuoso et al. 2002) or hens (Beaumont et al., 2003b). It is interesting to note that Caron et al., (2002) showed that the NRAMP1 allele coding for a better resistance of mice to an early and acute infection was also responsible for a higher excretion rate in later stages. This result has not yet been investigated in fowls. If it held, it could imply that selecting for the NRAMP1 allele coding for higher resistance to disease would result in a more intense excretion of Salmonella in the environment and thus quicker and more important transmission between animals. At the opposite, only the study of Beaumont et al (2003b) suspected a role of the TLR4 gene. Other candidate genes involved in the immune response were investigated using either polymorphisms within the gene or genetic markers (for a review, see Calenge et al (2010).

Searching for Quantitative Trait Loci (QTLs) is another way to identify genome regions involved in resistance. It is based on a systematic research of effects, on resistance, of anonymous genetic markers, chosen to cover as regularly as possible the whole genome. A first genome scan was achieved by Mariani et al., (2001) on resistance to disease due to Salmonella typhimurium. A major QTL controlling spleen bacterial load was identified on chromosome 5 and named SAL1. A 6th generation backcross allowed confirming and refining the QTL (Fife et al., 2009). It also suggested two very promising functional candidate genes, which should lead to the identification of the gene(s) underlying the QTL. Tilquin et al., (2005) identified QTL for resistance to both disease and carrier-state. One genome-wise significant QTL and five chromosome-wise significant QTL were observed on chromosomes 2, 1, 5, 11 and 16, respectively. This genome scan used selective genotyping (i.e. genotyping of only a subset of animals, chosen as particularly informative, because of extreme phenotypic values); two of those QTLs (on chromosomes 2 and 16) were confirmed after targeted genotyping of all animals (Calenge et al., 2009) while the QTLs on chromosomes 1 and 16 were also observed in the lines issued from the experiment of divergent selection on resistance to carrier-state described by Beaumont et al., (2010) (Calenge et al., 2009). More recently, the development of a new generation of genetic markers, Single Nucleotide Polymorphisms (SNP) allowed a denser coverage of the genome and the identification of new QTLs (Calenge et al., 2011; Fife et al., 2011) one of which is close to the zone observed on chromosome 2 by Fife et al. (2011). The results of all publications of QTL research are shown on Table 1.

Functional genomics compares the levels of expression (i.e. of activity) of genes at the genome-wide level. It allows the identification of genes involved in the mechanisms of resistance and may also lead to the identification of the genes controlling resistance, provided that the mutations responsible for differences in resistance also result in variations in the levels of expression. Studies compared levels of expression before and after infection, on animals from the same genotypes, or between animals issued from resistant and susceptible poultry lines (for a review, see Calenge et al., 2010). Focussing on the expression of candidate immune genes allows a better understanding of their role (as in Sadeyen et al., 2004; Sadeyen et al., 2006; Swaggerty et al., 2006) in relation with the type of cells as shown by Chausse et al., (2011), when comparing results obtained on the whole caeca by Sadeyen et al. (2004) to observations obtained on sorted cells from this organ. 


\begin{tabular}{c|c|l}
\hline Chromosome & $\begin{array}{c}\text { Position } \\
\text { (in cM or Mb) }\end{array}$ & \multicolumn{1}{|c}{ Reference } \\
\hline 1 & $\begin{array}{c}85,207 \mathrm{cM} \\
509 \mathrm{cM}\end{array}$ & $\begin{array}{l}\text { Tilquin et al., 2005 } \\
\text { Calenge et al., 2011 }\end{array}$ \\
\hline 2 & $\begin{array}{c}87 \mathrm{cM} \\
20 \mathrm{Mb}\end{array}$ & $\begin{array}{l}\text { Tilquin et al., 2005 } \\
\text { Fife et al., 2011 }\end{array}$ \\
\hline 3 & $123 \mathrm{cM}$ & $\begin{array}{l}\text { Calenge et al., 2011 } \\
\text { Fife et al., 2011 }\end{array}$ \\
\hline 4 & $96 \mathrm{Mb}$ & Calenge et al., 2011 \\
\hline 5 & $158,242 \mathrm{cM}$ & Mariani et al., 2001 \\
& $157 \mathrm{cM}$ & Tilquin et al., 2005 \\
& $100,111 \mathrm{cM}$ & Calenge et al., 2011 \\
\hline 6 & $38 \mathrm{cM}$ & Calenge et al., 2011 \\
\hline 9 & $8 \mathrm{cM}$ & Calenge et al., 2011 \\
\hline 11 & $68 \mathrm{cM}$ & Tilquin et al., 2005 \\
& $18 \mathrm{cM}$ & Calenge et al., 2011 \\
\hline 12 & $63 \mathrm{cM}$ & Fife et al., 2011 \\
\hline 14 & $15 \mathrm{Mb}$ & Calenge et al., 2011 \\
\hline 16 & $72,74,80 \mathrm{cM}$ & Tilquin et al., 2005 \\
\hline 18 & $2 \mathrm{cM}$ & Calenge et al., 2011 \\
\hline 22 & $12,14 \mathrm{cM}$ & Calenge et al., 2011 \\
\hline 24 & $29 \mathrm{cM}$ & Calenge et al., 2011 \\
\hline 25 & $41 \mathrm{cM}$ & Fife et al., 2011 \\
\hline 27 & $1 \mathrm{Mb} \mathrm{cM}$ & Calenge et al., 2011 \\
\hline
\end{tabular}

Table 1. Position of QTLs for resistance to Salmonella in chicken already published.

\subsection{Potential efficiency of marker assisted or genomic selection}

Using results currently available makes it possible to use marker-assisted selection. A first experiment of SNP-assisted selection was achieved by Legarra et al., (2011). A total of 600 animals were genotyped for 831 SNP; these markers explained a large proportion of genetic variance, even if no reduction in residual variance could be observed. This drawback will no doubt be alleviated when a larger number of SNP will be considered, leading to genomic selection, i.e. marker-assisted selection based on genotypes assessed on a very large number of anonymous markers, most often SNP (Meuwissen et al., 2001). Genomic selection investigates the whole genome at least as far as the markers cover it. Even if no application of this procedure to selection of commercial fowls is known yet, that should be the case in the near future. That should especially hold for traits whose measure is expensive and heritability low, as resistance related traits. It should also make it possible to select for several resistance related traits, even if genetic correlations are negative.

However, even with genomic selection, the choice of selection criteria remains a main issue. Whatever the method, it is not possible to consider the numerous resistance-related traits that might be measured using the different protocols of experimental infection described in subsection 2.1. It is necessary to find out the most important ones. Modelling will no doubt be of great interest for such studies. It will consider current knowledge on genetic resistance and other prophylactic means and investigate what may be expected from different methods of selection and prevention as well as from their combination. 


\section{Mathematical modelling: A way to integrate genetic results for a better understanding of Salmonella propagation within a flock of hens}

A few models have already been proposed to study Salmonella spread within hens (Leslie, 1996, Thomas et al., 2009; Prévost et al., 2006; Zongo et al, 2010a). In two models (Leslie, 1996; Thomas et al., 2009), the transmission of the Salmonella is determined by direct contact between animals and the density of bacteria in environment neglected. Prévost et al. (2006, 2007, 2008) and Zongo et al. (2010a) took into account the effect of the bacterial load of the environment. Variability in animal genetic resistance was introduced by Prévost et al, (2008). They distinguished two subpopulations of hens, with a lower or higher resistance to Salmonella carrier-state, as the model is a deterministic compartmental model (i.e. the population is divided into categories). In Zongo et al (2010a), individuals are represented, which makes it possible to model the contamination of each hen and to assume them to have varying degrees of resistance. In particular, effects of animal's capacity of defense on the evolution of the individual bacterial load were considered. Since the model is stochastic, the impact of this variability on propagation within the flock can be investigated.

\subsection{Model at the population level}

Classically, for a large population (as a flock), compartmental deterministic models are defined and the numbers of animals in each category are modelled. Prévost et al., (2006) developed such a model. These authors considered four categories of hens. Naïve (also called susceptible) birds have no protection against Salmonella: they are at risk of becoming infected. For hens' contamination, three steps were distinguished. The first is digestive contamination, when the bacteria are located in the digestive tract. Systemic infection occurs after translocation of bacteria through the digestive barrier; it results in contamination of systemic organs, such as liver or spleen, and sometimes also in egg contamination. Afterwards, bacterial clearance leads to recovery (see figure 1).

First contamination depends on the environmental bacterial load. Indeed, propagation of the infection may occur through aerosols from one contaminated animal to another animal, especially when they are reared in the same cage, or indirectly because of environmental contamination, mainly through water and feed. It is to note that this model neglected vertical transmission though transovarian route (Humphrey et al., 1989). Once contaminated at the digestive level, animals will become infected to a systemic level then get immunised. Thus, the rates of transition to the systemic level and, afterwards, the recovered status are constant.

Numerical analyses give hints for developing control measures as they highlight the influence of factors contributing to the variation of egg contamination and thus to the risk of human contamination. The recovery rate, representing the ability of hens to eliminate Salmonella, influences both maximal prevalence and duration of the epizooty. The rate of return to the susceptible state, i.e. the loss of protective immunity, is also of major importance. These results could be related to biological mechanisms. The mechanisms explaining the response to selection for a lower or higher contamination level were not the same. Selection on higher resistance had mostly modified the hen's clearance ability while a higher rate of return to the susceptible state was responsible for the higher level of contamination of the other line, which had a shorter immune protection time. This is coherent with results on immune response of lines differing (among other resistance traits) in resistance to carrier state, whether inbred (Sadeyen et al., 2006), or outbred (Proux et al., 2002; Protais et al., 2003). 


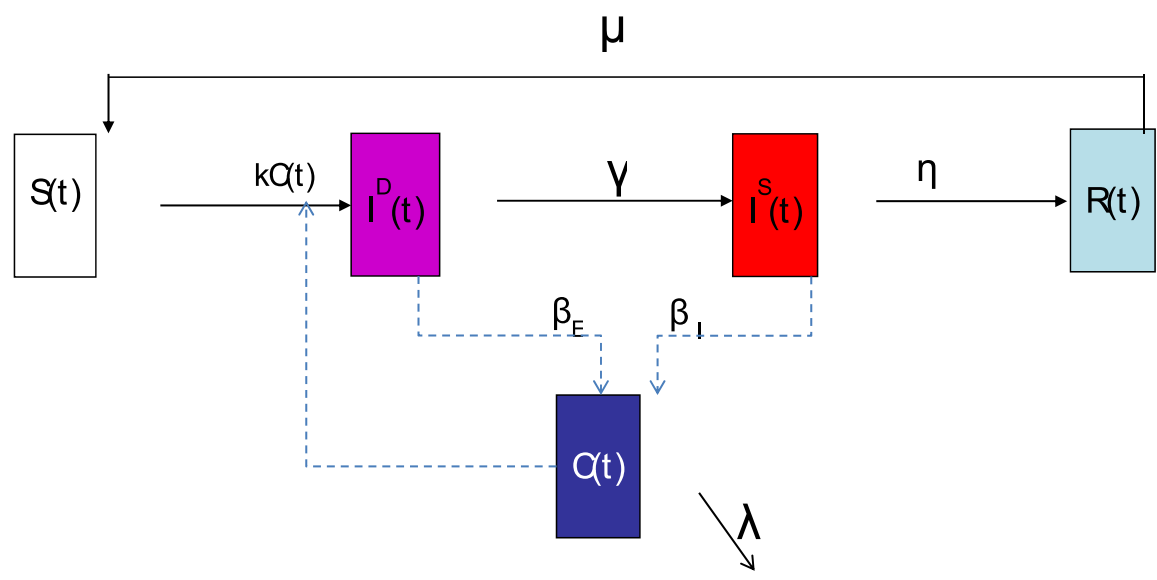

Fig. 1. Diagrammatic representation of the evolution of health status for an individual at a given time t: individual may be susceptible (S), infected at the digestive level (ID) or at the systemic level (IS) or recovered (R). $\beta_{\mathrm{E}}$ and $\beta_{\mathrm{I}}$ are the rates of excretion of infected animals at the digestive or systemic levels. They contribute to the increase in the number of bacteria in the environment. The rate of transition $(\mathrm{k} C(\mathrm{t}))$ from the susceptible $(\mathrm{S})$ to the infected at the digestive level $\left(\mathrm{I}^{\mathrm{D}}\right)$ status depends on the number of bacteria in the environment $(\mathrm{C}(\mathrm{t}))$. Parameters $\gamma, \eta$ and $\mu$, respectively, are the rates of transition from one status to another (i.e. from infected at the digestive (ID) to infected at the systemic level ( $\left.\mathrm{I}^{\mathrm{S}}\right)$, from infected at the systemic level $\mathrm{I}^{\mathrm{S}}$ to recovered (R) and from recovered to susceptible (S), respectively).

The effect of the introduction of a proportion of more resistant animals among the population was investigated. It reduces the peak of infection (i.e. the maximal percentage of infected animals), because the more resistant animals excrete less bacteria in the environment, reducing cross contamination. But it also delays the extinction of the epizooty as a higher proportion of animals are still naïve and infected later. Increasing genetic resistance to a greater extent but in a proportion of the population or increasing it to a lesser extent but in all animals will lead to different results. Inversely, results of genotype comparisons will not be the same when animals with different degrees of bacterial clearance are reared together or not. This point should be further studied in practice.

The effect of vaccination on flocks with different levels of genetic ability to clear bacteria was also investigated. The vaccine was more efficient in more resistant animals, in relation with the differences in the persistence of immunity. These differences are coherent with observations made by Protais et al. (2003). It is important to note that the combination of vaccination and genetic selection resulted in a percentage of contamination similar to what the European community is asking for.

\subsection{Taking into account the variability at the animal level}

A stochastic individual-based model was developed for a finer modelling of the variability of hen's response to contamination (Zongo et al., 2010a). Such models are largely used in ecology (Grimm et al., 2006) and were already used to model the growth and migration of Salmonella enteritidis in hens' eggs (Grijspeerdt et al., 2005). The model extends the model previously derived by Prévost et al. (2006). 
The variation over time (that is the derivative) of the individual bacterial load $B(\tau, x)$ was modelled as resulting from bacterial multiplication within the individual (i.e. growth rate), and from contamination by environmental bacteria. The latter was dependant on the number of bacteria present in the neighbourhood of the individual, that is the density of bacteria. It is to note that such a more precise modelling could also be derived using a deterministic approach as follows:

$$
\underbrace{\partial B(\tau, x) / \partial \tau}_{\text {Variation within individual }}=\underbrace{B(\tau, x))}_{\text {Growth rate }}+\underbrace{I_{P}(t, x)}_{\begin{array}{c}
\text { Inhaled or ingested } \\
\text { within environment }
\end{array}}
$$

Equation 1: Derivative, according to time, of individual bacterial load $(B(t, x)$ at time $t$ and position $x$ is equal to the sum of growth rate, $g$, of $B(t, x)$ and of contamination through ingestion or inhalation of bacteria present in in the neighbourhood, that is $\mathrm{I}_{\mathrm{p}}(\mathrm{C}(\mathrm{t}, \mathrm{x}))$. This derivative is computed at each time step and position.

Contrary to Prévost et al. (2008), two steps in digestive contamination were distinguished (Figure 2): a transient contamination and a long term one. When in the transient status, animals may overcome the contamination and get rid of the bacteria, provided that their bacterial load (thereafter denoted B) remains lower than a threshold D. Once the hen is contaminated at a bacteria load higher than D, its capacities of defence are overwhelmed and it will become systematically infected.

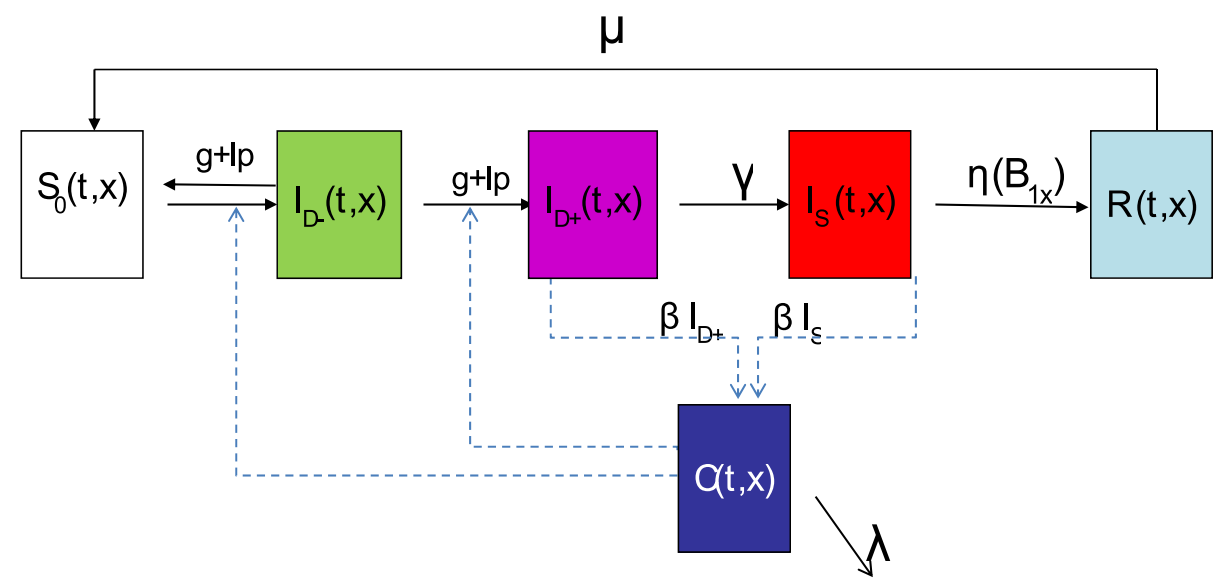

Fig. 2. Diagrammatic representation of the evolution of health status for an individual at time $t$ and position $\mathrm{x}$ and its interaction with the level of environmental contamination at this position, $\mathrm{C}(\mathrm{t}, \mathrm{x})$. The individual may be susceptible $\left(\mathrm{S}_{0}\right)$, infected at the digestive level with a low dose of contamination $\left(\mathrm{I}_{\mathrm{D}-}\right)$, suffering from a long term digestive contamination $\left(\mathrm{I}_{\mathrm{D}^{+}}\right)$, contaminated at the systemic level $\left(\mathrm{I}_{\mathrm{S}}\right)$ or recovered $(\mathrm{R})$. The number of bacteria carried by an

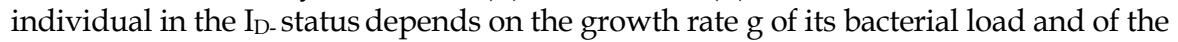
quantity of ingested bacteria; the latter depends on the level of environmental contamination in the neighbourhood $\left(I_{p(t, x)}\right)$. The individual bacterial load regulates transitions from $S_{0}$ to $I_{D-}$ (reciprocally from $I_{D-}$ to $S_{0}$ ) and from $I_{D-}$ to $I_{D+}$. Parameters $\gamma, \eta$ and $\mu$, respectively, regulates durations of status $I_{D^{+}}$, IS and $R$, respectively. $\beta_{\mathrm{D}+}$ and $\beta_{I}$ are the rates of excretion of infected animals at respectively the transient digestive and systemic level. 
Transitions from susceptible to digestive contamination status (both $I_{D-}$ and $I_{D+}$ ) are regulated by the individual bacterial load, which is computed at each time step and for each animal. When it is greater than zero and lower that the individual threshold, $\mathrm{D}(\mathrm{x})$, individual status changes from $S_{0}$ to $I_{D-}$. The individual may go back in $S_{0}$-state unless $\mathrm{B}\left(\mathrm{t}_{\mathrm{n}+1}, \mathrm{x}\right)$ becomes greater than $\mathrm{D}(\mathrm{x})$ and individual status changes from $\mathrm{I}_{\mathrm{D}-}$ to $\mathrm{I}_{\mathrm{D}^{+}}$. Other transitions are stochastic with average durations equal to $1 / \gamma, 1 / \eta\left(B_{1 x}\right)$ and $1 / \mu$, respectively, for the transitions from $I_{D^{+}}$-state to $I_{S}$-state, $I_{S^{-}}-$-state to $R$-state and from $R$ state to $S_{0}$ respectively.

The threshold $\mathrm{D}(\mathrm{x})$ is assumed to vary from an animal to another as it depends on many factors: the bacterial strain (as can be seen for example from Bumstead and Barrow, 1993), gut flora (Nurmi \& Rantala, 1973), animals' genetic resistance (§ 1). This variability and the differences in initial contamination result in a variability in bacterial load as can be seen in Figure 3.
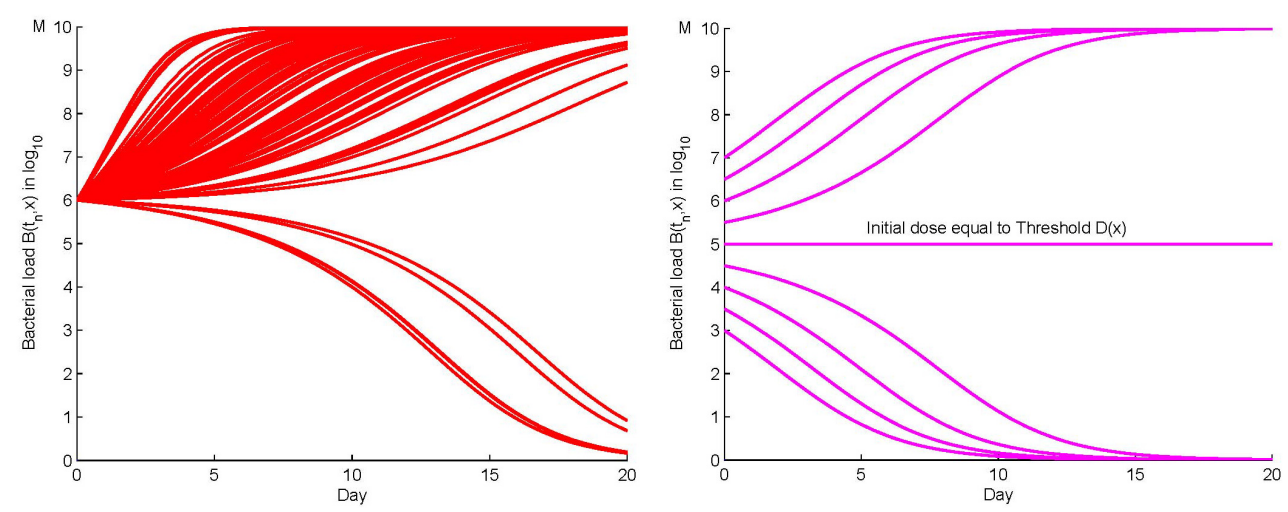

Fig. 3. Evolution of individual bacterial load $(B(t, x))$ within an individual at the position $x$ and time $t$ according to the number of bacteria ingested by the animal and the threshold for animals' ability to overcome the contamination $(\mathrm{D}(\mathrm{x}))$. $\mathrm{M}$ is the maximal bacterial load that an animal may carry (set here at $10 \log 10$ c.f.u.). In (a), $\mathrm{D}(\mathrm{x})$ is set to the same value for each animal (5 $\log 10$ c.f.u.). Four initial doses are above the threshold, one equal to it and four doses below it. In (b), the thresholds $\mathrm{D}$ are random, leading to different thresholds for each animal so that, for the same initial dose (set here at $6 \log 10$ c.f.u.), there is individual variability in evolution of the bacteria load.

The density of bacteria $(C(t, x))$ in the environment at time $t$ and position $x$ depends on the rate of diffusion of bacteria, on the natural rate of mortality of bacteria, $\lambda$, as well as on the density of bacteria excreted by infectious individuals close to position $\mathrm{x}$.

As the model is spatial, Zongo et al (2010a) show that the position of the first contamination influences both the kinetics of infection and the maximal percentages of infected animals (see figure 4). 

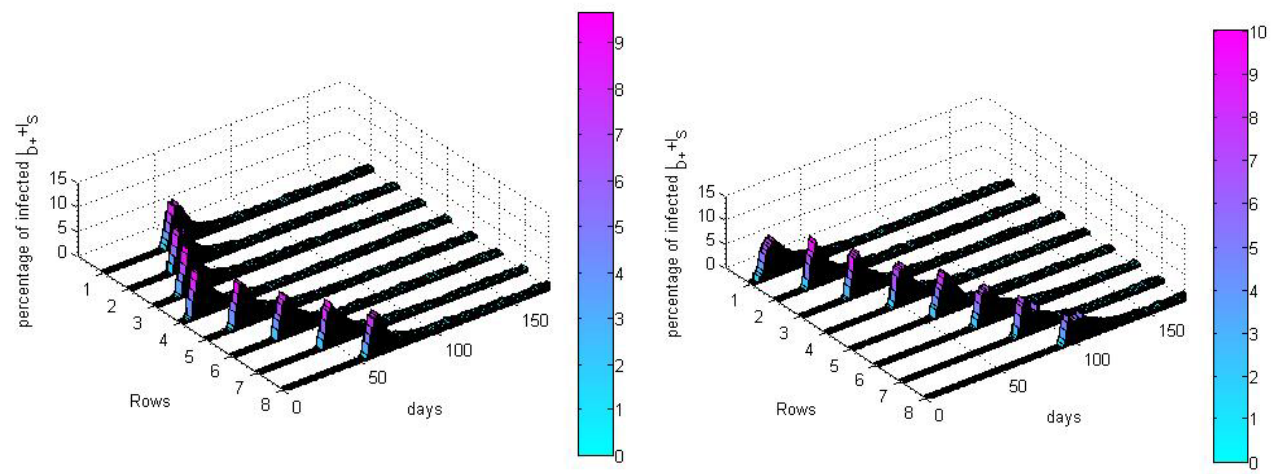

Fig. 4. Influence of the position of the first infection on the evolution over time of the percentage of infected animals (at the digestive level, in a persistent way $\left(I_{D^{+}}\right)$, or systematically ( $\left.\mathrm{I}_{\mathrm{S}}\right)$ ), when (a) infection starts in the middle (row 4 out of 8 ) or (b) in the corner of the hen house (row 1 out of 8 ). Only median values of the sum of percentages of infected animal are represented. The color bars indicate the relation between color and percentage of infected animals.

One investigation considered two levels of excretion, since it may vary between hens (Ishola, 2009). As can be seen on figure 5, both the propagation speed and the maximum level of infection are strongly influenced (Zongo et al, 2010b). But more studies are still needed to investigate this question.
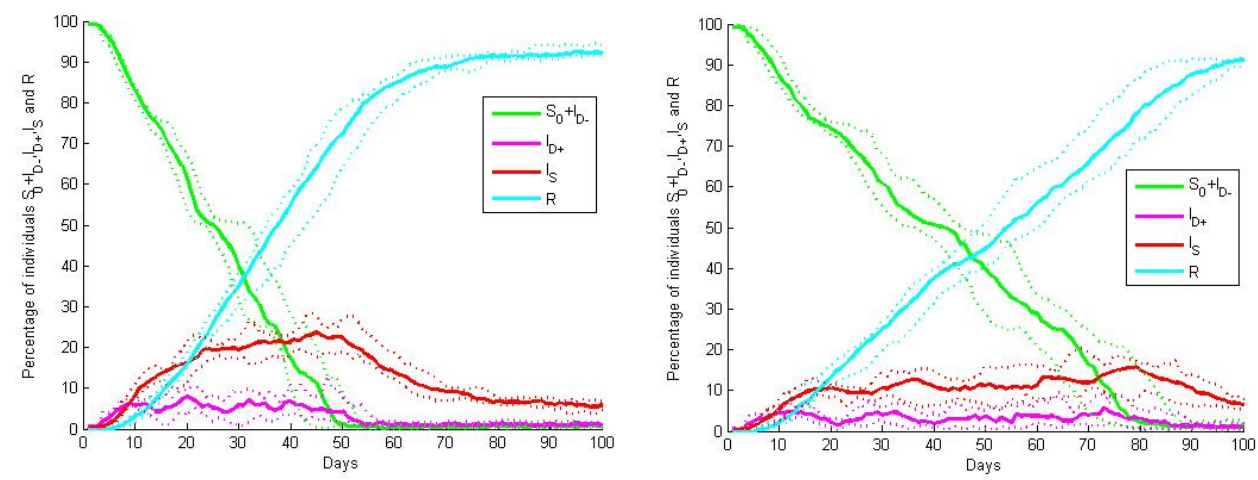

Fig. 5. Evolution of status of individuals (susceptible $\left(\mathrm{S}_{0}\right)$, infected at the digestive level with a low dose of contamination $\left(\mathrm{I}_{\mathrm{D}-}\right)$, suffering from a long term digestive contamination $\left(\mathrm{I}_{\mathrm{D}^{+}}\right)$, contaminated at the systemic level ( $\mathrm{I}_{\mathrm{S}}$ ) or recovered (R)), according to days after the first contamination, when (a) all individuals in the $\mathrm{I}_{\mathrm{D}+}$ or I-state excrete (b) half of individuals at

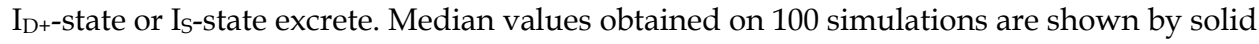
lines curves, while the 5 th and 95th percentiles are shown by dotted lines. 


\subsection{Perspectives}

First, the relative effects of animals' capacity of bacterial clearance and level of excretion should be studied. Both have important effects and most probably interact with each other and with the animals' capacities to overcome transient digestive contamination (threshold D). Since, in hen houses, bacterial doses are most often rather small, it will be important to study the effects of both average values and variability of these factors.

Second, interactions between animals may be more precisely modelled. The model derived by Zongo et al. (2010a) assumes that all hens within a cage are contaminated at the same time and carry the same bacterial load. When the number of hens within cage becomes large, this major hypothesis does not totally hold. Moreover, new systems of rearing should be considered, such as aviaries, extensive rearing or enriched cages. They should be more and more frequent with the European commission banning of traditional cages after 2012. They no doubt interact with sanitary risks. Salmonella propagation should also be considered in flocks of younger animals.

Rearing together animals with different profiles of resistance should also be considered. It is worth comparing whether it is more efficient to select one type of resistance (as for example capacity of bacterial clearance or low level of excretion) or several resistance-related traits. In particular, flocks composed of several lines selected on different resistance related traits or performance should be considered. At a longer term, such studies should integrate the links between immune capacities and performance, as investigated by Van der Most et al. (2010). Complementary studies should also consider egg yolk's genetic ability to resist bacterial infection as evidenced by Sellier et al., (2007).

\section{Conclusion}

Selection for higher resistance to carrier-state may be an efficient way to control Salmonella propagation within a flock. It might profitably be used as an additional mean of prevention of human food poisoning. The choice of the selection criteria must be considered carefully as it will have a strong influence on the results of selection. Other means of prevention must also be considered to choose the best strategy of prevention according to its impact on the level of animal contamination and then on the Salmonella propagation. Modelling will contribute to integrate genetic and experimental data at individual level to evaluate the propagation at the population level. It will allow the comparison of the impact of different scenarios on the propagation within a flock with, for example, different profiles of resistance or different prophylactic measures. Reversely, these studies will ask new questions and necessitate new experiments to confirm results or give values of some parameters. In particular, if the resistance and the propagation are different according to Salmonella strains, different models can be developed, providing there are sufficient data to define them. For other pathogenic agents, such as Campylobacter, integrated studies should also be envisaged.

\section{Acknowledgment}

The grants Aliment Demain SF20 from French Ministries of Research and of Agriculture, RESISAL from French National Agency for Research, as well the help of the Region Centre and of the EADGENE Network of Excellence are greatly acknowledged. Pascal Zongo benefited from a post-doctoral scholarship from the INRA direction. The authors are 
grateful to all those who contributed to these studies, in particular to experimental units Pole d'Expérimentation Avicole de Tours et Plate-Forme d'Infectiologie Expérimentale who reared animals. The help of Nathaele Wacrenier for literature review is acknowledged.

\section{References}

Beaumont, C.; Protais, J.; Guillot, J.; Colin, P.; Proux, K.; Millet, N. \& Pardon, P. (1999). Genetic Resistance to Mortality of Day-Old Chicks and Carrier-Sate of Hens after Inoculation with Salmonella Enteritidis. Avian Pathology, Vol. 28, No. 2, (Avril 1999.), pp. (131-135), ISSN 0307-9457

Beaumont, C.; Dambrine, G.; Chaussé, A.-M. \& Flock, D. (2003a). Selection for Disease Resistance: Conventional Breeding for Resistance to Bacteria and Viruses, In: Poultry Genetics, Breeding and Biotechnology, W. Muir \& S. Aggrey (Eds.), pp. (357382), CAB International, ISBN 0-85199-660-4, Oxon, UK

Beaumont, C.; Protais, J.; Pitel, F.; Leveque, G.; Malo, D.; Lantier, F.; Plisson-Petit, F.; Colin, P.; Protais, M.; Roy, P. L.; Elsen, J.; Milan, D.; Lantier, I.; Neau, A.; Salvat, G. \& Vignal, A. (2003b). Effects of Two Candidate Genes on the Salmonella Carrier-State in Fowl. Poultry Science, Vol. 82, No. 5, (May 2003.), pp. (721-726), ISSN 0032-5791

Beaumont, C.; Chapuis, H.; Sellier, N.; Calenge, F.; Zongo, P.; Velge, P. \& Protais, J. (2009). Selection for Increased Resistance to Salmonella Carrier-State. World Poultry Science Association (WPSA), 6th European Poultry Genetics Symposium, Bedlewo, Poland, 30 September - 2 October, 2009, pp. (26-35)

Beaumont, C.; Chapuis, H.; Sellier, N.; Calenge, F.; Zongo, P.; Velge, P. \& Protais, J. (2010). Selection for Increased Resistance to Salmonella Carrier-State. Worlds Poultry Science Journal, Vol. 66, No. 2, (June 2010), pp. (251-259), ISSN 0043-9339

Bumstead, N. \& Barrow, P. (1988). Genetics of Resistance to Salmonella Typhimurium in Newly Hatched Chicks. British Poultry Science, Vol. 29, No. 3, (September 1988), pp. (521-529), ISSN 0007-1668

Bumstead, N. \& Barrow, P. (1993). Resistance to Salmonella Gallinarum, S. Pullorum and S. Enteritidis in Inbred Lines of Chickens. Avian Diseases, Vol. 37, No. 1, (January 1993.), pp. (189-193), ISSN 0005-2086

Calenge, F.; Lecerf, F.; Demars, J.; Feve, K.; Vignoles, F.; Pitel, F.; Vignal, A.; Velge, P.; Sellier, N. \& Beaumont, C. (2009). Qtl for Resistance to Salmonella Carrier State Confirmed in Both Experimental and Commercial Chicken Lines. Animal Genetics, Vol. 40, No. 5, (April 2009), pp. (590-597), ISSN 0268-9146

Calenge, F.; Kaiser, P.; Vignal, A. \& Beaumont, C. (2010). Genetic Control of Resistance to Salmonellosis and to Salmonella Carrier-State in Fowl: A Review. Genetics Selection Evolution, Vol. 42, No. 11, (April 2010), doi:10.1186/1297-9686-42-11, ISSN 0999-193X

Calenge, F.; Vignal, A.; Demars, J.; Feve, K.; Menanteau, P.; Velge, P. \& Beaumont, C. (2011). New Qtl for Resistance to Salmonella Carrier-State Identified on Fowl Microchromosomes. Molecular Genetics and Genomics, Vol. 285, No. 3, pp. (237243), ISSN 1617-4615

Caron, J.; Loredo-Osti, J.; Laroche, L.; Skamene, E.; Morgan, K. \& Malo, D. (2002). Identification of Genetic Loci Controlling Bacterial Clearance in Experimental Salmonella Enteritidis Infection: An Unexpected Role of Nramp1 (Slc11a1) in the Persistence of Infection in Mice. Genes and Immunity, Vol. 3, No. 4, (June 2002), pp. 196-204, ISSN 1466-4879 
Chaussé, A. M.; Grépinet, O.; Bottreau, E.; Le Vern, Y.; Menanteau, P.; Trotereau, J.; Robert, V.; Kaiser, P.; Kerboeuf, D.; Beaumont, C. \& Velge, P. (2011). Expression of TLR4 and downstream effectors in selected caecal cell sub-populations of chicks resistant or susceptible to Salmonella carrier-state. Infection and Immunity, Vol.79, No. 8, (August 2011), pp (3445-3454), ISSN : 0019-9567

Curtiss, R. III; Xin, W.; Li Y.; Kong, W.; Wanda, S.Y. ; Gunn, B. \& Wang, S.F. (2010). New Technologies in Using Recombinant Attenuated Salmonella Vaccine Vectors. Criticial reviews in immunology. Vol. 30, No. 3, pp (255-270), ISSN: 1040-8401.

DeVolt, H.; Quigley, G. \& Byerly, T. (1941). Studies of Resistance to Pullorum Diseases in Chickens. Poultry Science, Vol. 20, No. 4, pp. (339-341), ISSN 0032-5791

Duchet-Suchaux, M.; Léchopier, P.; Marly, J.; Bernardet, P.; Delaunay, R. \& Pardon, P. (1995). Quantification of Experimental Salmonella Enteritidis Carrier State in B13 Leghorn Chicks. Avian Diseases, Vol. 39, No. 4, (October-December 1995) pp. (796803), ISSN 0005-2086

Duchet-Suchaux, M.; Mompart, F.; Berthelot, F.; Beaumont, C.; Léchopier, P. \& Pardon, P. (1997). Differences in Frequency, Level and Duration of Cecal Carriage between Four Outbred Chicken Lines Infected Orally with Salmonella Enteritidis. Avian Diseases, Vol. 41, No. 3, (July-September 1997), pp. (559-567), ISSN 0005-2086

EFSA. (2007a). The Community Summary Report on Trends and Sources of Zoonoses, Zoonotic Agents, Antimicrobial Resistance and Foodborne Outbreaks in the European Union in 2005, EFSA, Retrieved from http://www.efsa.europa.eu/EFSA/efsa_locale1178620753812_1178620767319.htm

EFSA. (2007b). Report of the Task Force on Zoonoses Data Collection on the Analysis of the Baseline Survey on the Prevalence of Salmonella in Broiler Flocks of Gallus Gallus, in the Eu, 2005-2006. The EFSA Journal, Vol. 98, No 2, (April 2007.), pp. (1-85) ISSN 1831-4732

EFSA. (2011). The European Union Summary Report on Trends and Sources of Zoonoses, Zoonotic Agents and Food-borne Outbreaks in 2009. The EFSA Journal, Vol. 9, No. 3, (March 2010), pp. (2090-2367), ISSN 1831-4732

Fife, M.; Salmon, N.; Hocking, P. \& Kaiser, P. (2009). Fine Mapping of the Chicken Salmonellosis Resistance Locus (Sal1). Animal Genetics, Vol. 40, No. 6, (December 2009), pp. (871-877), ISSN 0268-9146

Fife, M.; Howell, J.; Salmon, N.; Hocking, P.; van Diemen, P.; Jones, M.; Stevens, M. \& Kaiser, P. (2011). Genome-Wide Snp Analysis Identified Major Qtl for Salmonella Colonization in the Chicken. Animal Genetics, Vol. 42, No. 2, (April 2011), pp. (134140), ISSN 0268-9146

Ghebremicael, S.B.; Hasenstein, J.R.\& Lamont, S. (2008). Association of interleukin-10 cluster genes and Salmonella response in the chicken. Poultry Science, Vol. 87, No. 1, (January 2008), pp (22-26), ISSN 0043-9339

Girard-Santosuosso, O. (1997). Partial Conservation of the Mammalian Nramp1 Syntenic Group on Chicken Chromosome 7. Mammalian Genome, Vol. 8, (August 2007), pp. (614-616) ISSN 0938-8990

Girard-Santosuosso, O.; Lantier, F.; Lantier, I.; Bumstead, N.; Elsen, J.-M. \& Beaumont, C. (2002). Heritability of Susceptbility to Salmonella Enteritidis Infection in Fowls and Test of the Role of the Chromosome Carrying the Nramp1 Gene. Genetic Selection Evolution, Vol. 342, (April 2002), pp. (211-219), ISSN 0999-193X

Grijspeerdt, K.; Kreft, J. U. \& Messens, W. (2005). Individual-Based Modelling of Growth and Migration of Salmonella Enteritidis in Hens' Eggs. International Journal of Food Microbiology, Vol. 100, No. 1-3, (April 2005), pp. (323-333), ISSN 0168-1605 
Grimm, V.; Berger, U.; Bastiansen, F.; Eliassen, S.; Ginot, V.; Giske, J.; Goss-Custard, J.; Grand, T.; Heinz, S. K.; Huse, G.; Huth, A.; Jepsen, J. U.; Jorgensen, C.; Mooij, W. M.; Müller, B.; Pe'er, G.; Piou, C.; Railsback, S. F.; Robbins, A. M.; Robbins, M. M.; Rossmanith, E.; Rüger, N.; Strand, E.; Souissi, S.; Stillman, R. A.; Vabo, R.; Visser, U. \& DeAngelis, D. L. (2006). A Standard Protocol for Describing Individual-Based and Agent-Based Models. Ecological Modelling, Vol. 198, No. 1-2, (June 2006), pp. 115-126), ISSN 0304-3800

Guillot, J.; Beaumont, C.; Bellatif, F.; Mouline, C.; Lantier, F.; Colin, P. \& Protais, J. (1995). Comparison of Resistance of Various Poultry Lines to Infection by Salmonella Enteritidis. Veterinary Research, Vol. 26, No. 2, pp. (81-86), ISSN 0928-4249

Hasenstein, J. R. \& Lamont, S. J. (2007). Chicken Gallinacin Gene Cluster Associated with Salmonella Response in Advanced Intercross Line. Avian Diseases, Vol. 51, No. 2, (June 2007), pp. (561-567), ISSN 0005-2086

Hu, J.; Bumstead, N.; Burke, D.; FA, P. d. L.; Skamene, E.; Gros, P. \& Malo, D. (1995). Genetic and Physical Mapping of the Natural Resistance-Associated Macrophage Protein 1 (Nramp1) in Chicken. Mammalian Genome, Vol. 6, No. 11, (November 1995), pp. (809-815), ISSN 0938-8990

Hu, J.; Bumstead, N.; Skamene, E.; Gros, P. \& Malo, D. (1996). Structural Organization, Sequence, and Expression of the Chicken Nramp1 Gene Encoding the Natural Resistance-Associated Macrophage Protein 1. DNA Cell Biol, Vol. 15, No. 2, (February 1996), pp. (113-123), ISSN 1044-5498

Hu, J.; Bumstead, N.; Barrow, P.; Sebastiani, G.; Olien, L.; Morgan, K. \& D, M. (1997). Resistance to Salmonellosis in the Chicken Is Linked to Nramp1 and Tnc. Genome Research, Vol. 7, No. 7, (July 1997), pp. (693-704), ISSN 1088-9051

Humphrey, T.J.; Baskerville, A.; Mawer, S.; Rowe, B, \& Hopper, S. (1989). Salmonella Enteritidis Phage Type 4 From The Contents Of Intact Eggs: A Study Involving Naturally Infected Hens. Epidemiology and Infection, Vol. 103, No. 3, (December 1989), pp.(415-423), ISSN 0950-2688

Humphrey, T. J. (1990). Public Health Implications of Infection of Egg-Laying Hens with Salmonella Enteretidis Phage Type 4. World Poultry Science Association Journal, Vol. 46, No. 1, (March 1990), pp. 5-13, ISSN 0043-9339

Hutt, F. \& Scholes, J. (1941). XIII. Breed Differences in Susceptibility to Salmonella Pullorum. Poultry Science, Vol. 20, No. 4, (July 1941), pp. 342-352, ISSN 0032-5791

Ishola, O. O. (2009) Effects Of Challenge Dose On Faecal Shedding Of Salmonella Enteritidis In Experimental Infected Chickens. African Journal of Biotechnology , Vol. 8, No. 7, (April 2009), pp. (1343-1346), ISSN 1684-5315

Janss, L. L. G. \& Bolder, N. M. (2000). Heritabilities of and Genetic Relationships between Salmonella Resistance Traits in Broilers. Journal of Animal Science, Vol. 78, No. 9, (September 2000), pp. (2287-2291), ISSN 0021-8812

Kramer, J.; Malek, M. \& Lamont, S. (2003). Association of Twelve Candidate Gene Polymorphisms and Response to Challenge with Salmonella Enteritidis in Poultry. Animal Genetics, Vol. 34, No. 5, (October 2003), pp. (339-348), ISSN 0268-9146

Lambert, W. \& Knox, C. (1928). The Inheritance of Resistance to Fowl Typhoid in Chickens. Iowa State Journal of Science, Vol. 2, pp. (179-187)

Lambert, W. V. (1932). Natural Resistance to Disease in the Chicken. Natural Resistance to disease in the chickens. III The Comparative Resistance of Different Breeds. Journal of Immunology, Vol. 23, No.3, (September 1932), pp. (253-259) , ISSN 0022-1767

Lamont, S.; Kaiser, M. \& Liu, W. (2002). Candidate Genes for Resistance to Salmonella Enteritidis Colonization in Chickens as Detected in a Novel Genetic Cross. 
Veterinary Immunology and Immunopathology, Vol. 87, No. 3-4, (September 2002), pp. (423-428), ISSN 0165-2427

Legarra, A.; Calenge, F.; Mariani, P.; Velge, P. \& Beaumont, C. (2011). Use of a Reduced Set of Single Nucleotide Polymorphisms for Genetic Evaluation of Resistance to Salmonella Carrier State in Laying Hens. Poultry Science, Vol. 90, No. 4, (April 2011), pp. (731-736), ISSN 0032-5791

Leslie, J. (1996). Simulation of the Transmission of Salmonella Enteritidis Phage Type 4 in a Flock of Laying Hens. Veterinary Record, Vol. 139, No. 16, (October 1996), pp. (388391), ISSN 0042-4900

Leveque, G.; Forgetta, V.; Morroll, S.; Smith, A.; Bumstead, N.; Barrow, P.; Loredo-Osti, J.; Morgan, K. \& Malo, D. (2003). Allelic Variation in Tlr4 Is Linked to Susceptibility to Salmonella Enterica Serovar Typhimurium Infection in Chcickens. Infection and Immunity, Vol. 71, No. 3, (March 2003), pp. (1116-1124), ISSN 0019-9567

Lindell, K.; Saeed, A. \& McCabe, G. (1994). Evaluation of Resistance of Four Strains of Commercial Laying Hens to Experimental Infection with Salmonella Enteritidis Phage Type Eight. Poultry Science, Vol. 73, No. 6, (June 1994), pp. (757-762), ISSN 0032-5791

Liu, W.; Miller, M. \& Lamont, S. (2002). Association of Mhc Class I and Class I Gene Polymorphisms with Vaccine or Challenge Response to Salmonella Enteritidis in Young Chicks. Immunogenetics, Vol. 54, No. 8, (November 2002), pp. (582-590), ISSN 0093-7711

Mariani, P.; Barrow, P.; Chang, H.; Groenen, M.; Negrini, R. \& Bumstead, N. (2001). Localization to Chicken Chromosome 5 of a Novel Locus Determining Salmonellosis Resistance. Immunogenetics, Vol. 53, No. 9, (December 2001), pp. (786791), ISSN 0093-7711

Meuwissen, T.; Hayes, B. \& Goddard, M. (2001). Prediction of Total Genetic Value Using Genome Wide Dense Marker Maps. Genetics, Vol. 157, No. 4, (April 2001), pp. (1819-1829), ISSN 0016-6731

Nurmi, E. \& Rantala, M. (1973). New Aspects of Salmonella Infection in Broiler Production. Nature, Vol. 241, No. 5386, (January 1973), pp. (210-211), ISSN 0028-0836

Prévost, K.; Magal, P. \& Beaumont, C. (2006). A Model of Salmonella Infection within Industrial House Hens. Journal of Theoretical Biology, Vol. 242, No. 3, (October 2006), pp.( 755-763), ISSN: 0022-5193

Prévost, K, ; Magal, P.; Protais, J. \& Beaumont, C. (2008), Effect of hens' genetic resistance to Salmonella carrier-state on incidence of bacterial contamination: synergy with vaccination, Veterinary Research, Vol. 39, No. 2, (March-April 2008), doi: 10.1051/vetres:2007058, ISSN 0928-4249

Prévost, K. ; Beaumont, C. \& Magal, P. (2007), Asymptotic behavior in a Salmonella Infection Model, Mathematical Modelling of Natural Phenomena, Vol. 2, No. 1, (January 2007), pp. (1-22), ISSN: 0973-5348

Protais, J.; Nagard, B.; Boscher, E.; Queguiner, S.; Beaumont, C. \& Salvat, G. (2003). Changes in Salmonella Enteritidis Contamination in Two Layer Lines Vaccinated During the Rearing Period. British Poultry Science, Vol. 44, No. 5, (December 2003), pp. (827828), ISSN 0007-1668

Protais, J.; Colin, P.; Beaumont, C.; Guillot, J.; Lantier, F.; Pardon, P. \& Bennejean, G. (1996). Line Differences in Resistance to Salmonella Enteritidis Pt4 Infection, Poultry Science, Vol. 37, No. 2, (May 1996), pp.(329-339), ISSN 0007-1668

Proux, K.; Jouy, E.; Houdayer, C.; Protais, J.; Dibb-Füller, M.; Boscher, E.; Gillard, A.; Gracieux, P.; Gilbert, F.; Beaumont, C. \& Duchet-Suchaux, M. (2002). Reliable Elisas Showing Differences between Resistant and Susceptible Lines in Hens Orally 
Inoculated with Salmonella Enteritidis. Veterinary Research, Vol. 33, No. 1, (JanuaryFebruary 2002), pp. (23-33), ISSN 0928-4249

Sadeyen, J.-R.; Trotereau, J.; velge, P.; Marly, J.; Beaumont, C.; Barrow, P.; Bumstead, N. \& Lalmanach, A.-C. (2004). Salmonella Carrier State in Chicken: Comparison of Expression of Immune Response Genes between Susceptible and Resistant Animals. Microbes and Infection, Vol. 6, No. 14, (November 2004), pp. (1278-1286), ISSN 1286-4579

Sadeyen, J.-R.; Trotereau, J.; Protais, J.; Beaumont, C.; Sellier, N.; Salvat, G.; Velge, P. \& Lalmanach, A.-C. (2006). Salmonella Carrier-State in Hens: Study of Host Resistance by a Gene Expression Approach. Microbes and Infection, Vol. 8, No. 5, (April 2006), pp. (1308-1314), ISSN 1286-4579

Sellier, N.; Vidal, M. L.; Baron, F.; Michel, J.; Gautron, J.; Protais, M.; Beaumont, C.; Gautier, M. \& Nys, Y. (2007). Estimations of Repeatability and Heritability of Egg Albumen Antimicrobial Activity and of Lysozyme and Ovotransferrin Concentrations. British Poultry Science, Vol. 48, No. 5, (October 2007), pp. (559-566), ISSN 0007-1668

Swaggerty, C.; Kaiser, P.; Rothwell, L.; Pevzner, I. \& Kogut, M. (2006). Heterophil Cytokine Mrna Profiles from Genetically Distinct Lines of Chickens with Differential Heterophil-Mediated Innate Immune Responses. Avian Pathology, Vol. 35, No. 2, (April 2006), pp. (102-109), ISSN 0307-9457

Thomas, M. E.; Klinkenberg, D.; Ejeta, G.; Knapen, F. V.; Bergwerff, A. A.; Stegeman, J. A. \& Bouma, A. (2009). Quantification of Horizontal Transmission of Salmonella Enterica Serovar Enteritidis Bacteria in Pair-Housed Groups of Laying Hens. Applied and Environmental Microbiology, Vol. 75, No. 19, (October 2009), pp. (6361-6366), ISSN 0099-2240

Tilquin, P.; Barrow, P.; Marly, J.; Pitel, F.; Plisson-Petit, F.; Velge, P.; Vignal, A.; Baret, P.; Bumstead, N. \& Beaumont, C. (2005). A Genome Scan for Quantitative Trait Loci Affecting the Salmonella Carrier-State in the Chicken. Genetics Selection Evolution, Vol. 37, No. 5, (September-October 2005), pp. 539-561, ISSN 0999-193X

Van der Most, P. J.; De Jong, B.; Parmentier, H. K. \& Verhulst, S. (2010) Ecological immunology Trade-Off Between Growth And Immune Function: A Meta-Analysis Of Selection Experiments. Functional Ecology. Vol. 25, No. 1, (February 2011), pp. (74-80), doi: 10.1111/j. pp. 1365-2435. 2010.01800.x, ISSN 0269-8463

Vidal, S.; Tremblay, M.; Govoni, G.; Gauthier, S.; Sebastiani, G.; Malo, D.; Skamene, E.; Olivier, M.; Jothy, S. \& Gros, P. (1993). The Ity/Lsh/Bcg Locus: Natural Resistance to Infection with Intracellular Parasites Is Abrogated by Disruption of the Nramp1 Gene. Journal of Experimental Medicine,, Vol. 182, No. 3, (September 1995), pp. (655666), ISSN 0022-1007

Zhang-Barber, L.; Turner, A. K. \& Barrow, P. A. (1999). Vaccination for Control of Salmonella in Poultry. Vaccine, Vol. 17, No. 20-21, (June 1999), pp. (2538-2545), ISSN 0264-410X

Zongo, P.; Viet, A.-F.; Magal, P. \& Beaumont, C. (2010a). A Spatio-Temporal Model to Describe the Spread of Salmonella within a Laying Flock. Journal of Theoretical Biology, Vol. 267, No. 4, (December 2010), pp. (595-604), ISSN 0022-5193

Zongo, P.; Viet, A.F.; Magal, P. \& Beaumont, C. (2010b). A Model Of Spatio-Temporal Propagation Of Salmonella Considering The Animal Immune Response, European Poultry Conference, Tours, France, August 24-26, 2010. 
(C) 2012 The Author(s). Licensee IntechOpen. This is an open access article distributed under the terms of the Creative Commons Attribution 3.0 License, which permits unrestricted use, distribution, and reproduction in any medium, provided the original work is properly cited. 